\title{
CAI Combustion with Methanol and Ethanol in an Air-Assisted Direct Injection SI Engine
}

\author{
Yufeng Li \\ Ford Motor Company
}

\begin{abstract}
Hua Zhao and Nikolaos Brouzos
\end{abstract}
Brunel University

\begin{abstract}
CAl combustion has the potential to be the most clean combustion technology in internal combustion engines and is being intensively researched. Following the previous research on CAI combustion of gasoline fuel, systematic investigation is being carried out on the application of bio-fuels in CAI combustion. As part of an on-going research project, CAI combustion of methanol and ethanol was studied on a single-cylinder direct gasoline engine with an air-assisted injector. The CAI combustion was achieved by trapping part of burnt gas within the cylinder through using short-duration camshafts and early closure of the exhaust valves. During the experiment the engine speed was varied from 1200rpm to $2100 \mathrm{rpm}$ and the air/fuel ratio was altered from the stoichiometry to the misfire limit. Their combustion characteristics were obtained by analysing cylinder pressure trace. The experimental results show that both oxygenate fuels, methanol and ethanol, can lead to CAI combustion as well as gasoline fuel. The load of CAI combustion was increased and emissions were lower with the two oxygenate fuels. Methanol was found to have highest output and lowest energy consumption among the three fuels tested. CAl combustion characteristics of the oxygenate fuels were more affected by the amount of burnt residuals trapped than that of gasoline fuel.
\end{abstract}

\section{INTRODUCTION}

CAI (controlled auto-ignition) combustion is a new innovative gasoline technology in which the air/fuel mixture is ignited spontaneously like in diesel engine combustion. It has received much attention in recent years due to its high potential for increasing fuel economy and simultaneously decreasing NOx emissions. For a certain fuel CAI combustion can be realized by increasing the charge temperature which can be achieved via heating or boosting intake air [1,2], increasing compression ratio $[3,4]$ and re-circulating exhaust gas [513]. In practice, exhaust gas recirculation (EGR) has been shown the most effective and feasible way not only in initiating CAl combustion by charge heating but also in controlling the heat release rate by charge dilution. It can be obtained by external EGR [5], re-breathing exhaust gases $[6,7]$, trapping residuals in the cylinder by early closure of the exhaust valves (i.e. internal EGR) [8-13]. New valve technologies, variable valve train (VVT) or variable valve actuation (VVA) [8-13], have made internal EGR to be more popular.

Compared with current spark-ignited (SI) direct injection technology, CAl technique has the following benefits except for dramatic improvement in fuel economy:

(1) CAl technique does not require such careful organization in mixing strategy and optimization between in-cylinder flow, fuel spray and chamber geometry as the CAI combustion is mainly controlled by charge temperature for a certain fuel.

(2) It is not necessary to use expensive lean NOx catalytic converters which are still in development to meet much more stringent emission regulations in the future as such large amount of EGR is responsible for reducing NOx.

(3) The risk of smoke or soot may be reduced due to homogeneous mixture instead of charge stratification. However, application of CAI combustion still faces challenges in obtaining reliable auto-ignition, controlling ignition and combustion phases, enlarging CAI operation range, smoothly transmitting between $\mathrm{CAl}$ and $\mathrm{SI}$ combustion modes.

Even with EGR and VVT technology, CAI combustion still is not able to be applied into GDI (gasoline direct injection) products soon due to the above challenges. One of the ways to overcome those challenges is to use different fuels which have properties benefit to CAl combustion. Aaron Oaklay[14] and Xie Hui [15] have investigated the CAl combustion of methanol and ethanol fuels on a port injection engine and found that both oxygenate fuels had shown easier initiation of CAl combustion, wider CAI operating range and lower NOx emission than those of gasoline counterpart. However, these results on port injection gasoline engines can not be applied in direct injection gasoline engines due to different mixture preparation and combustion process. CAl combustion characteristics of methanol and ethanol in direct injection engines are still unclear and need to be investigated. In addition, different engine types, designs and techniques have increased the complexity of research.

This paper focuses on CAI combustion with methanol and ethanol in a single-cylinder GDI engine. CAI combustion 
of gasoline fuel was also analyzed in order to compare the oxygenate fuels.

\section{ENGINE AND EXPERIMENT}

\section{ENGINE}

The engine used in the experiment is a Ricardo Hydra single cylinder research engine with a prototype GDI cylinder head supplied by Orbital Engine Corporation Ltd. The engine has a bore of $80 \mathrm{~mm}$ and a stroke of $89 \mathrm{~mm}$. The compression ratio is 10:1. The cylinder head features a centrally mounted fuel injector, pent roof combustion chamber with four valves (in Fig.1) and double overhead camshafts. The injectors are a spray guided air-assisted type $[16,17]$. It consists of a direct injector and a conventional multi-point fuel injection (MPI) injector behind it. The fuel is first injected into a chamber behind the direct injector by the MPI injector with an absolute pressure of 8bar. The direct injector then injects not only the fuel metered by the MPI injector but also a quantity of compressed air into the cylinder with a pressure of 6.5 bar, giving an excellent atomization.

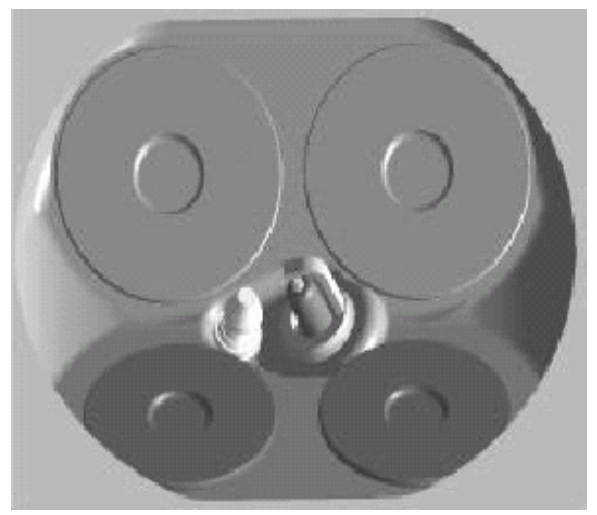

Fig.1 Structures of the combustion chamber

In order to trap sufficient amounts of residual gases in the cylinder to initiate CAI combustion, the original intake and exhaust camshafts were substituted by those with low lift and short duration as shown in Fig.2. It should be noted that the TDC of intake is taken as " 0 " in the paper as shown in Fig.2 except in Fig.5 where "0" means the TDC of compression. The camshafts can be turned freely with respect to tooth pulley after loosing two connection bolts so as to change the valve timing. As early closure of exhaust valves, the cylinder pressure is firstly increased by compression of the remained residuals and then decreased by expansion of them to form a recompression and re-expansion process around TDC of the intake as shown in Fig.5(a). The early closure of the exhaust valves dictates that the intake valve opening (IVO) timing should be delayed to prevent excessive back-flow of trapped residuals into the intake manifold.

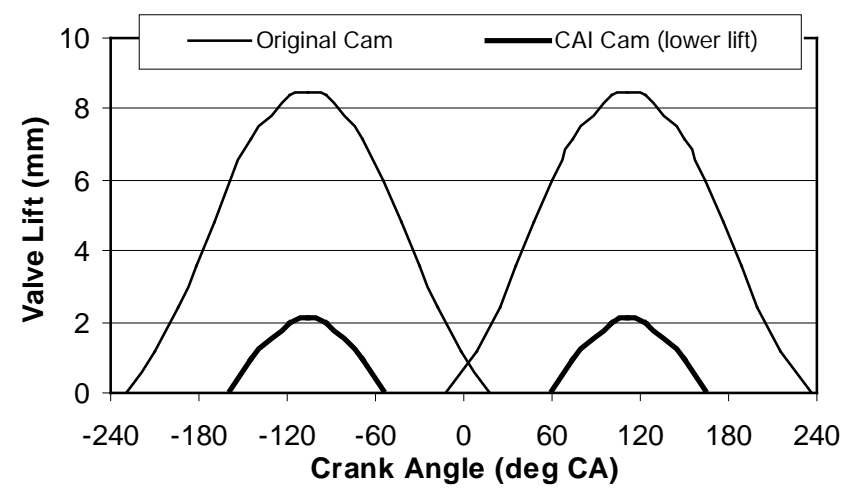

Fig.2 Valve lift history for original and CAI cams

\section{FUELS}

Fuels used in the experiments are gasoline, methanol and ethanol. Table 1 shows their properties. The following different properties can be seen:

- Stoichiometric A/F ratio: because of the presence of oxygen element both oxygenate fuels have lower stoichiometric air/fuel ratio. This means that burning a given mass of oxygenate fuels need less air than burning the same mass of gasoline.

- Octane number: methanol and ethanol have higher octane number than gasoline. This will affect their auto-ignition and combustion processes. In general higher octane number fuel is more difficult to selfignite.

- Low heating value (LHV): heating value of methanol is only half of that of gasoline. Ethanol has one-third lower heating value than gasoline. This means that mass fuel consumption of the three fuels will be different for the same engine output. Therefore, specific energy consumption is used in the paper to compare fuel consumption between the fuels.

- LHV of stoichiometric mixture: although the three fuels have different LHV, the LHV of stoichiometric mixture remains similar.

- Heat of vaporization: methanol has 3.5 times higher and ethanol 1.5 times higher in heat of vaporization than gasoline fuel. This means that vaporizing a certain amount of oxygenate fuels need absorb much more heat from the surroundings than vaporizing the same mass of gasoline fuel. This property may give oxygenate fuels (especially methanol) such different mixture preparation compared to gasoline fuel: lower charge temperature if the mixture is homogenous, or more complicate thermal distribution if the mixture is not uniformly distributed. Thus, the autoignition and CAl combustion process will be affected.

- Auto-ignition temperature: gasoline has lower autoignition temperature than methanol. This also affects the initiation of CAI combustion. 


\begin{tabular}{|c|c|c|c|}
\hline & $\begin{array}{c}\text { Gasoline } \\
\left(\mathrm{C}_{\mathrm{n}} \mathrm{H}_{1.87 \mathrm{n}}\right)\end{array}$ & $\begin{array}{c}\text { Methanol } \\
\left(\mathrm{CH}_{3} \mathrm{OH}\right)\end{array}$ & $\begin{array}{c}\text { Ethanol } \\
\left(\mathrm{C}_{2} \mathrm{H}_{5} \mathrm{OH}\right)\end{array}$ \\
\hline $\begin{array}{c}\text { Stoichiometric A/F } \\
\text { ratio }\end{array}$ & 14.6 & 6.47 & 9.00 \\
\hline $\begin{array}{c}\text { Density }(\mathrm{kg} / \mathrm{m3}) \\
\mathrm{RON}\end{array}$ & $720-780$ & 792 & 785 \\
\hline $\mathrm{MON}$ & $80-90$ & 92 & 89 \\
\hline $\begin{array}{c}\text { Low heating value } \\
(\mathrm{MJ} / \mathrm{kg})\end{array}$ & 44 & 20 & 26.9 \\
\hline $\begin{array}{c}\text { Heat of vaporization } \\
(\mathrm{kJ} / \mathrm{kg})\end{array}$ & 305 & 1103 & 840 \\
\hline $\begin{array}{c}\text { LHV of stoich. Mixture } \\
(\mathrm{MJ} / \mathrm{kg})\end{array}$ & 2.83 & 2.68 & 2.69 \\
\hline $\begin{array}{c}\text { Auto-ignition } \\
\text { temperature }\left({ }^{\circ} \mathrm{C}\right)\end{array}$ & $260-460$ & 460 & 360 \\
\hline
\end{tabular}

\section{EXPERIMENT}

Before starting the engine, the coolant water and lubricant oil were heated to $85^{\circ} \mathrm{C}$. When starting, the engine was motored to $1200 \mathrm{rpm}$ and then activated the

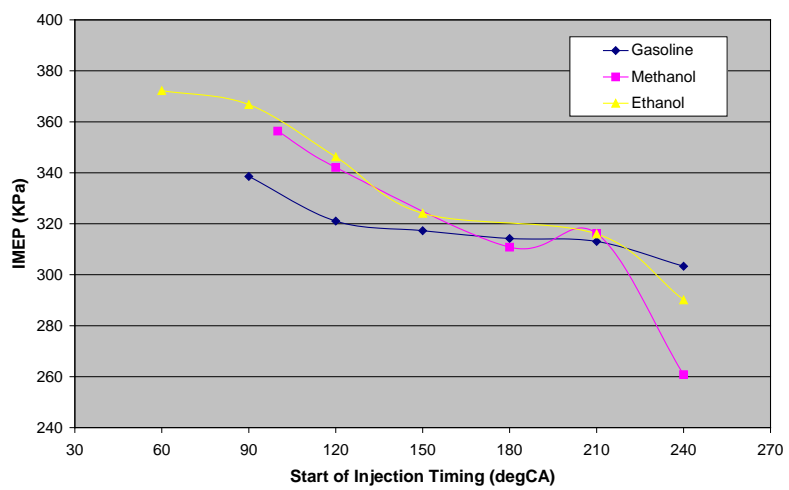

(a) IMEP

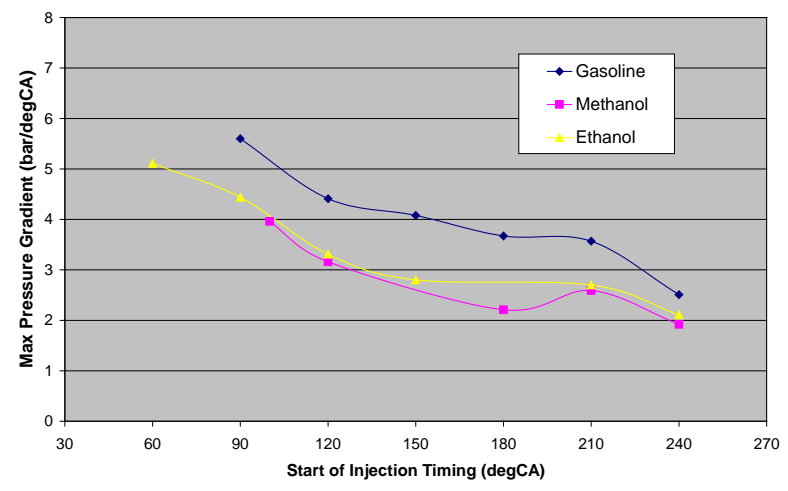

(c) Max pressure gradient

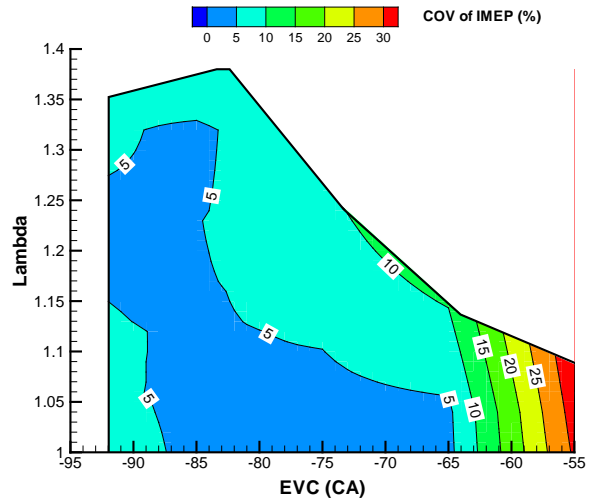

Fig.3 EVC timing range for CAI combustion [17] (Gasoline, SOI $=180^{\circ} \mathrm{CA}, \mathrm{n}=1800 \mathrm{rpm}$ )

Exhaust valve closure (EVC) timing determined the residual amount and charge temperature and hence initiation of self-ignition. It has been found that when the engine was fuelled with gasoline, CAI combustion was able to obtain on the EVC timing of $-60^{\circ} \mathrm{CA}$ (i.e. $60^{\circ} \mathrm{CA}$ BTDC) and $-95^{\circ} \mathrm{CA}$ as shown in Fig. 3 [17]. The top curve in Fig. 3 was constrained by the lean limit. With CAI combustion the coefficient of variation (COV) in indicated

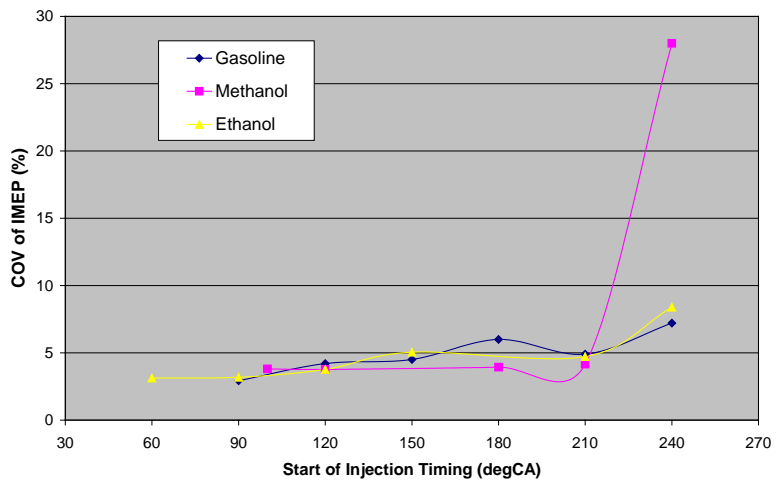

(b) COV of IMEP

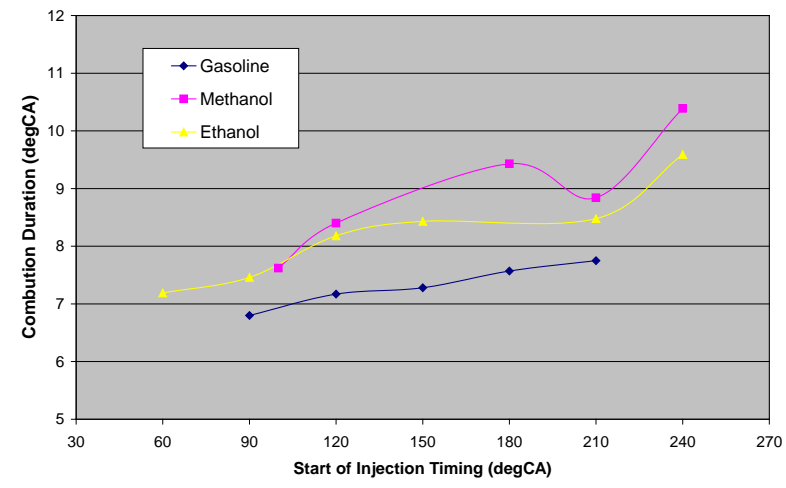

(d) $10 \%-90 \%$ burn rate

Fig.4 Effect of SOI timing on CAI combustion (EVC $=-70^{\circ} \mathrm{CA}, n=1800 \mathrm{rpm}, \lambda=1.0$ )

fuel injection and spark ignition. The engine might operate unstably in the beginning due to high residual amount trapped. The CAI combustion could be achieved as the engine speed was continued to increase carefully. The engine speed of CAI combustion initiation varied with the EVC (exhaust valve closure) timing, injection timing, A/F ratio and fuels. mean effective pressure (IMEP) was very low (less than 10\%). Too late EVC timing would cause the engine operation unstable as the residual amount is too low to initiate CAI combustion and on the other hand too much to achieve a stable SI combustion. Too early EVC timing gave too much residual, suppressing the combustion. In this paper experiments were conducted at the EVC timing 
of $-70^{\circ} \mathrm{CA}$ and $-85^{\circ} \mathrm{CA}$.

The start of injection (SOI) timing also has an important effect on CAl combustion. The CAI combustion could be achieved on the SOI timing between $60^{\circ} \mathrm{CA}$ and $240^{\circ} \mathrm{CA}$ in the intake process and early compression process. Before $60^{\circ} \mathrm{CA}$ and after $240^{\circ} \mathrm{CA}$, the fuel was not able to inject properly into the cylinder as the cylinder pressure was close to or higher than the injection pressure (6.5bar).

Fig.4 shows effect of SOI on CAI combustion for the three fuels. It is clearly seen that as the SOI was retarded from $60^{\circ} \mathrm{CA}$ to $240^{\circ} \mathrm{CA}$, IMEP and the maximum pressure gradient reduced, whilst COV of IMEP and combustion duration (defined as crank angle from $10 \%$ to $90 \%$ of mass burn) increased. Early injection (SOI $\left.=60^{\circ} \mathrm{CA}-90^{\circ} \mathrm{CA}\right)$ gave high pressure gradient (Fig.4(c)) and late injection $\left(240^{\circ} \mathrm{CA}\right)$ caused high pressure cyclic variation (Fig.4(b)). In the following experiments, the SOI timing was fixed at $120^{\circ} \mathrm{CA}$.

During the experiments, the air/fuel ratio, along with $\mathrm{CO}$ and $\mathrm{CO}_{2}$ emissions, were measured using a standard Horiba exhaust gas analyzer, while NOx and HC

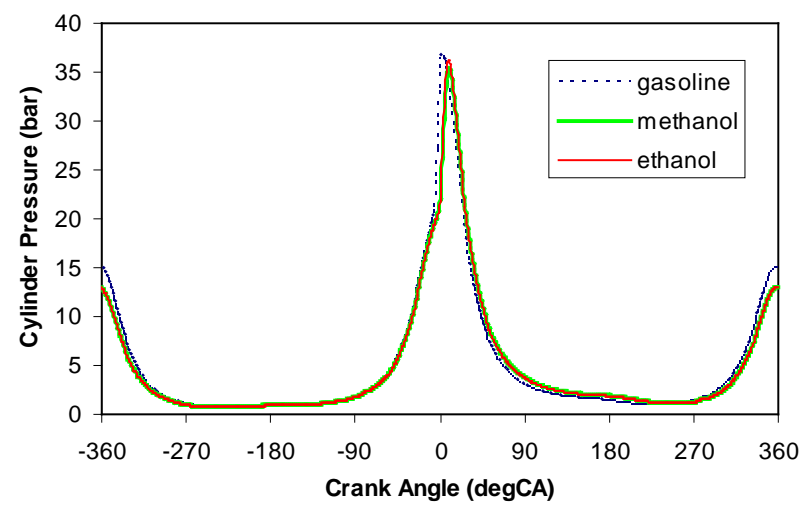

(a) Cylinder pressure release and other combustion parameters. In order to describe combustion characteristics conveniently, the crank angle of $10 \%$ mass burnt is referred to the start of combustion (SOC) and the crank angle between $10 \%$ and $90 \%$ of mass burnt is defined as the combustion duration. The exhaust gas temperature was measured using a thermocouple located in the exhaust port.

The relationship of fuel injection volume and injection pulse width was carefully calibrated at the given injection pressure of 6.5 bar. The actual fuel mass flow rate was obtained by interpolating the calibration curve according to the actual pulse width measured. Air mass flow rate was then calculated by timing the fuel flow rate with the A/F ratio measured. Thus, the accuracy of the fuel and air mass flow closely relies on the fuel injection calibration and A/F ratio measurement. This could give an error up to $5 \%$.

Another important experimental error comes from the measurement of EVC timing. EVC timing was given by a graduated disc which was marked at every two degrees and was pasted on the pulley. The EVC timing was read when the pulley was in loose. However, when being

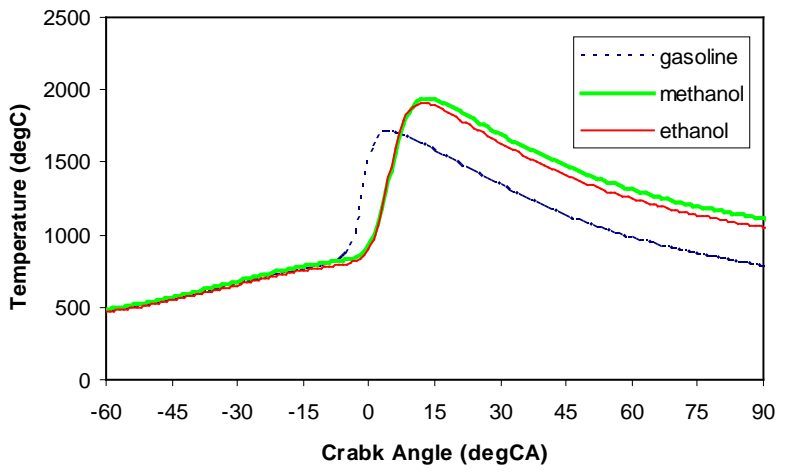

(b) Cylinder temperature

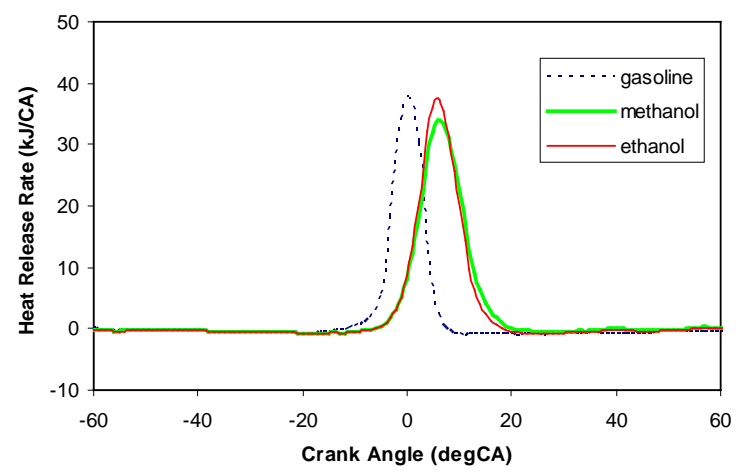

(c) Heat release rate

Fig.5 Cylinder pressure, temperature and heat release rate for gasoline, methanol and gasoline $\left(E V C=-70^{\circ} \mathrm{CA}, \mathrm{n}=1800 \mathrm{rpm}, \lambda=1.0\right.$ )

emissions were measured using Signal NOx and FID (Flame Ionization Detection) analyzers respectively. Cylinder pressure data was measured by a piezo-electric pressure transducer and was subsequently recorded using a PC based data acquisition system. Off-line post processing was then conducted to extract the heat tightened, the pulley would have a little sliding against the camshaft, causing an EVC timing error of $+/-3^{\circ} \mathrm{CA}$. 


\section{RESULTS AND ANALYSES}

\section{COMBUSTION AT EVC OF $-70^{\circ} \mathrm{CA}$}

Cylinder pressure and heat release rate Fig. 5 shows the trace of cylinder pressure, temperature and heat release rate for the three fuels at $E V C=-70^{\circ} \mathrm{CA}$, $n=1800$ rpm and stoichiometric mixture $(\lambda=1)$. It is seen that CAI combustion with gasoline fuel obtained the earliest start of combustion and the highest maximum cylinder pressure (Fig.5(a) and (c)) but the lowest maximum-cylinder-temperature. Methanol and ethanol had similar values in pressure, temperature and heat release rate at the operating point.

The cylinder temperature was estimated from the idea gas law:

$$
T=\frac{P V}{n R}
$$

In which $\mathrm{P}, \mathrm{V}, \mathrm{T}$ is the cylinder pressure, volume and temperature, respectively. $\mathrm{R}$ is the universal gas constant. $\mathrm{n}$ is the mole number of the charge which includes fresh air, fuel and burnt residuals and should vary with the degree of combustion. As an approximation, $\mathrm{n}$ was taken as a constant here and can be obtained from air and fuel mass flow rates and EGR mass trapped in the cylinder. EGR mass trapped was estimated from the idea gas law as well in which the pressure and the volume took their values at the EVC timing and the temperature was replaced by the exhaust temperature measured.

In traditional SI engines, methanol and ethanol are burnt with lower temperature than gasoline. In the study, however, due to earlier start of combustion and larger mole number gasoline fuel shows lower temperature in Fig.5(b) than methanol and ethanol fuels even though gasoline fuel had the maximum cylinder pressure as shown in Fig.5(a).

CAl combustion at different mixture concentration Fig.6 shows CAl combustion characteristics versus mixture concentration at operating conditions of EVC=$70^{\circ} \mathrm{CA}, \mathrm{SOI}=120^{\circ} \mathrm{CA}$ and $\mathrm{n}=1800 \mathrm{rpm}$. It appears that both methanol and ethanol had similar CAI characteristics, much different from those of gasoline. The details are as follows:

- Fig.6(a) shows that methanol had highest IMEP while gasoline took the lowest value (Fig.6(a)) at the operating conditions. Ethanol obtained the output between them. The high output of the oxygenate fuels is attributed to their high heat of vaporization (thus high volumetric efficiency), right combustion or heat release phasing and high octane number (in Table 1). This implies that the load region of CAl combustion would increase by about $15 \%$ when using the oxygenate fuels.

- It is observed in Fig.6(b) that the three fuels had similar value in COV of IMEP at the stoichiometric mixture $\lambda=1.0$. As the mixture turned lean, gasoline fuel still kept the COV value as low as $5 \%$ until $\lambda=1.4$. However, COV of IMEP for methanol and ethanol fuels increased rapidly at about $\lambda=1.2$. This indicates that the two oxygenate fuels had much leaner mixture limit than gasoline fuels at the tested conditions.

- CAl combustion of gasoline fuel had much higher pressure gradient than that of the two oxygenate fuels as seen in Fig.6(c). This is a combined result of less EGR rate required (Fig.6(d)), much earlier start of combustion (Fig.6(e)) and much shorter combustion duration (Fig.6(f)) for the gasoline fuel case.

- EGR rate was defined as a ratio of EGR mass trapped at EVC and the whole intake charge mass in the cylinder. At the tested conditions more percentage of burnt gas were trapped in the cylinder for the oxygenate fuels than gasoline fuel (Fig.6(d)). EGR rate is determined by not only the mass of intake charge but also the pressure at EVC which is associated to the combustion process.

- Gasoline fuels presented much earlier and faster combustion than methanol and ethanol at the tested conditions. A reason was that the gasoline fuel has less EGR rate (Fig6(d)) and lower autoignition temperature (Table1). The other important reason may be related to complicated fuel/air/EGR distribution and thermal distribution within the cylinder between the three fuels. This will be discussed in next section.

- Although both oxygenate fuels had higher output (IMEP) than gasoline fuel, their indicated specific energy consumptions (ISEC in Fig6(g)) were lower than gasoline. This implies that methanol and ethanol had higher thermal efficiency as shown in Fig.6(h). One reason of lower thermal efficiency of gasoline may be attributed to too early (a few crank angles before TDC) and too fast combustion which caused negative force against piston.

- Fig.6(i) shows that maximum cylinder temperature of both oxygenate fuels was higher than that of gasoline on all achievable mixture concentration range. Methanol presented highest maximum temperature. As mentioned before, earlier start of combustion and larger mole number lead to lower temperature for the gasoline fuel case.

- Both oxygenate fuels were observed to have much lower HC, CO and NOx emissions than those of gasoline. In particular, gasoline fuel gave higher NOx emission despite lower combustion temperature (Fig6.(i)). NOx emission depends on not only combustion temperature but also EGR amount and distributions in air/fuel and temperature. One cause of higher NOx in gasoline 


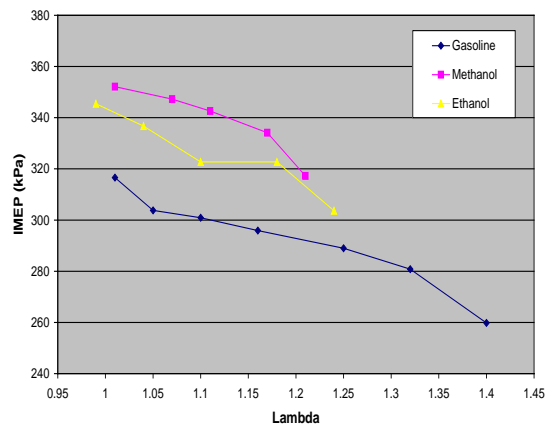

(a) IMEP

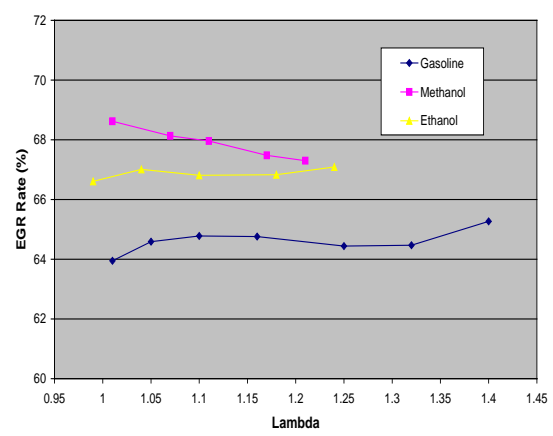

(d) EGR trapped rate

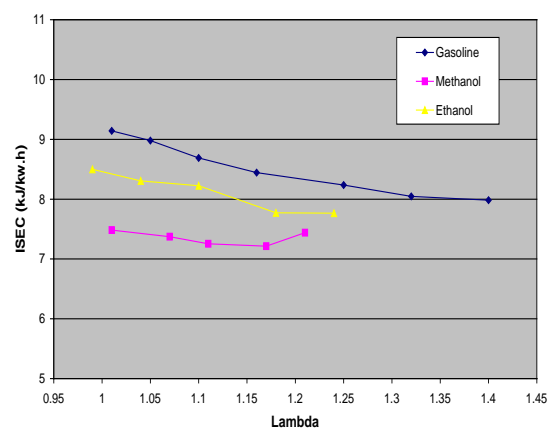

(g) Indicated specific energy consumption

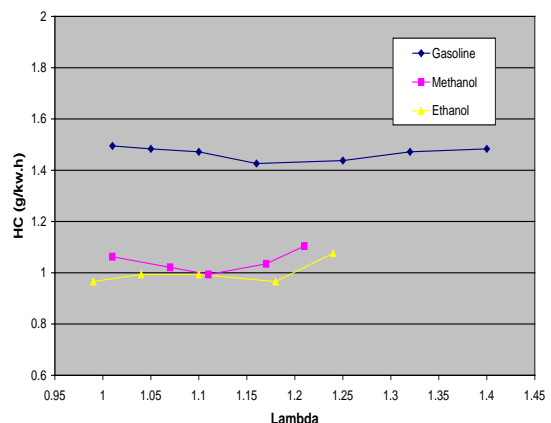

(j) $\mathrm{HC}$ emission

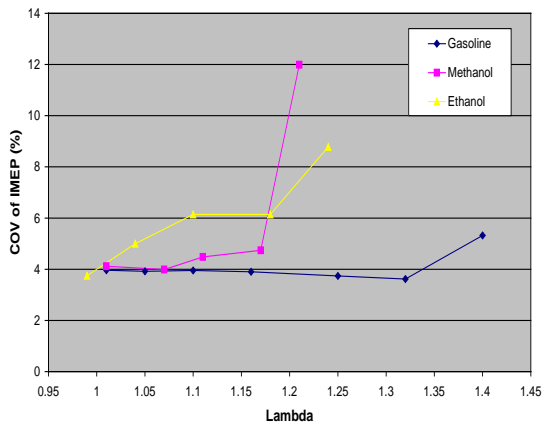

(b) COV of IMEP

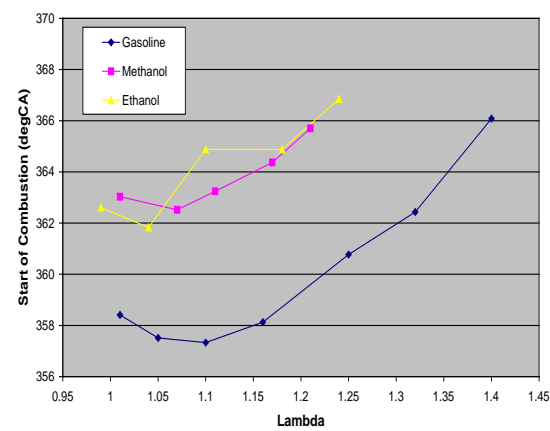

(e) start of combustion (CA at 10\% burn)

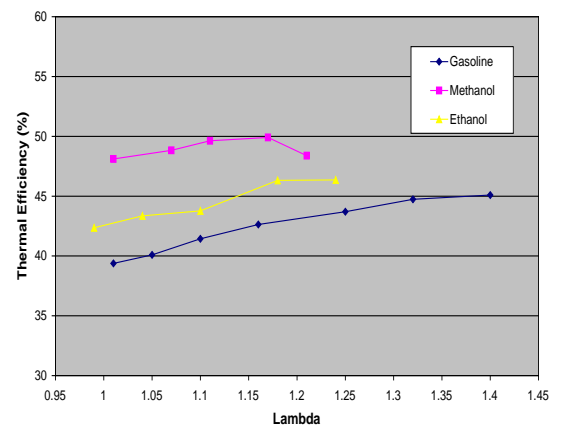

(h) Indicated thermal efficiency

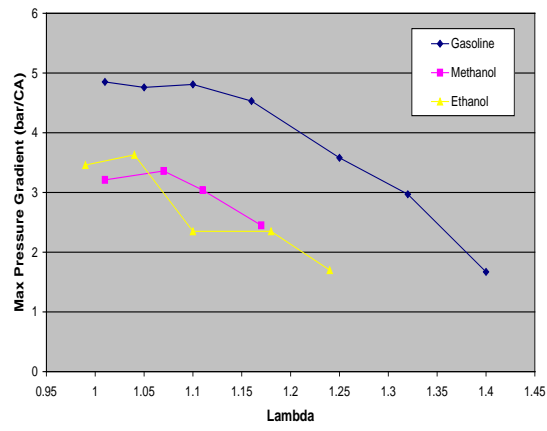

(c) Max pressure gradient

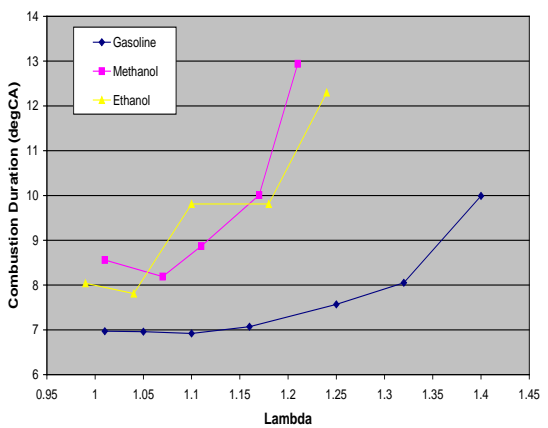

(f) Combustion duration (10-90\% burn)

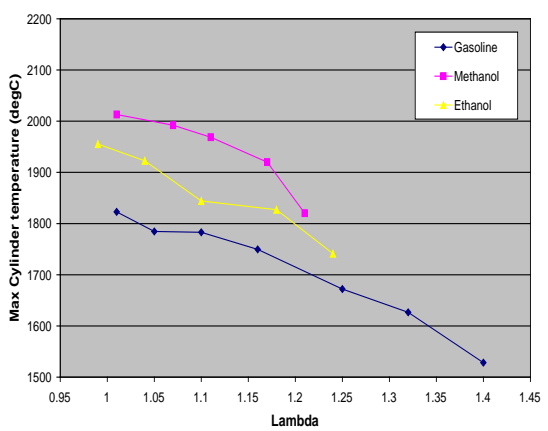

(i) Max cylinder temperature

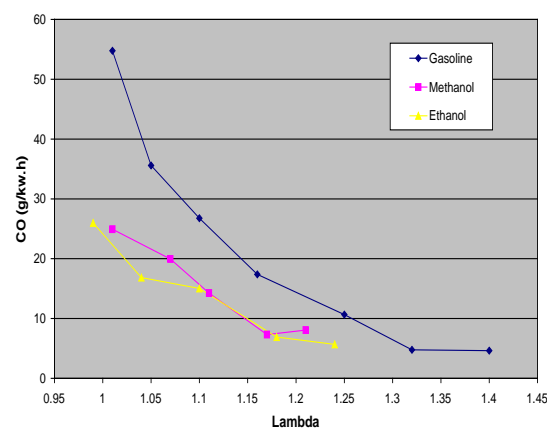

(k) CO emission

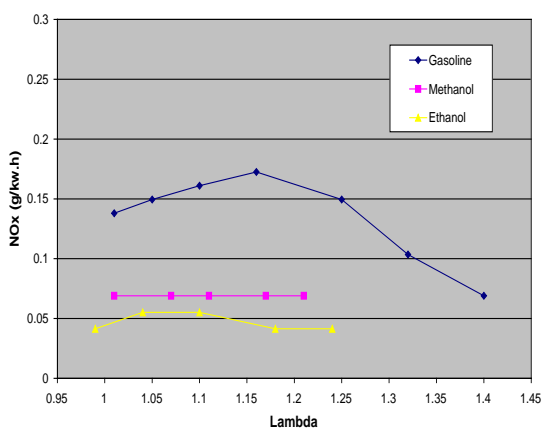

(I) NOx emission

Fig.6 CAl combustion characteristics with Lambda for gasoline, methanol and ethanol

$\left(E V C=-70^{\circ} \mathrm{CA}, \mathrm{SOI}=120^{\circ} \mathrm{CA}, \mathrm{n}=1800 \mathrm{rpm}\right)$ 
case may be its lower EGR rate (Fig.6(d)). Other causes may link to complicated air/fuel and thermal distributions which still remain unclear. Emission results indicate that methanol and ethanol could be more clean fuels than gasoline when they are applied in CAI combustion engine.

\section{COMBUSTION AT EVC OF $-85^{\circ} \mathrm{CA}$}

CAl combustion at different mixture concentration Fig.7 shows CAl combustion characteristics versus mixture concentration at operating conditions EVC=$85^{\circ} \mathrm{CA}, \quad \mathrm{SOI}=120^{\circ} \mathrm{CA}$ and $\mathrm{n}=1800 \mathrm{rpm}$. The detail analyses are given as follows:

- IMEP in Fig7(a): Like above results, methanol produced highest IMEP output among the tested fuels and gasoline did lowest IMEP which was $30 \%$ lower than that of methanol.

- COV of IMEP in Fig.7(b): it is seen that this parameter in methanol fuel case was about $4 \%$ for all mixture concentration until $\lambda=1.4$. Ethanol fuel gave the similar lower COV value until $\lambda=1.32$ and then COV value increased rapidly. The rapid increase of COV value for gasoline fuel was started at $\lambda=1.17$. This result demonstrates that methanol could keep very stable CAI combustion in wider mixture concentration range, much wider than that gasoline fuel could give.

- Maximum pressure gradient (Fig.7(c)): methanol presented highest pressure gradient among the three fuels. Gasoline and ethanol had similar value of max pressure rise at around $\lambda=1$ and then ethanol took lower value than gasoline.

- Combustion (Fig.7(d)-(f)): methanol was seen to start CAI combustion earlier and to have shorter combustion duration as well than the other two counterparts. Ethanol shows latest and slowest combustion among the three fuels, especially in lean mixture region. Methanol took the highest EGR rate at the tested conditions.

- Fuel conversion efficiency (Fig.7(g)-(i)): similar as the result at the EVC of $-70^{\circ} \mathrm{CA}$, methanol presented lowest energy consumption and highest thermal efficiency and then followed with ethanol. Gasoline produced lowest efficiency. Variation of the fuel conversion efficiency with fuels linked closely to the combustion temperature. Highest maximum-combustion-temperature of methanol produced highest fuel conversion efficiency. It should be noted here that the indicated thermal efficiency given in Fig.7(h) may be higher than they should be. The error may attribute to the uncertainty of fuel and air measurements. As mentioned in experiment section, fuel and air mass flow rate was calculated from the measured air/fuel ratio and fuel injection calibration. Any shot-by-shot variation in injection and cycle-bycycle variation in cylinder pressure and air/fuel ratio can further increase the error in efficiency calculation.

- Emissions (Fig.7(j)-(I)): methanol fuel presented lowest $\mathrm{HC}$ and NOx emissions among the three fuels. But $\mathrm{CO}$ emission was similar. NOx emissions were hardly changed with the mixture concentration. This is because the NOx instrument has low response to very low NOx value.

CAl combustion at different engine speed Fig.8 shows variation of COV of IMEP versus IMEP and engine speed for the three tested fuels at $E V C=-85^{\circ} \mathrm{CA}$ and $\mathrm{SOI}=120^{\circ} \mathrm{CA}$. In these contour maps the top curve was determined by the stoichiometric operation and the bottom curve was determined by the lean burn limit. The left side was determined by the minimum engine speed able to achieve stable CAl combustion. The right side was constrained by the speed of 2100rpm over which the experiment was not conducted. It can be seen that

- Gasoline fuel could obtain stable CAI combustion at 1200rpm, but the oxygenate fuels had to increase the minimum CAl available speed to about 1500rpm. As the EGR amount trapped increased with the increase of the engine speed, the above phenomenon implies that at the tested conditions methanol and ethanol require more EGR or heating to initiate CAI combustion than gasoline fuel. This is definitely related to these fuel properties: the oxygenate fuels have higher values of vaporizing heat and auto-ignition temperature (in Table1).

- With CAI combustion, the oxygenate fuels produced higher output (IMEP) than gasoline fuel in both stoichiometric and lean mixture operations. This indicates that the allowable CAI operation load would move up when substituting gasoline with methanol or ethanol. However, the load region (IMEP difference between stoichiometric operation and lean limit) was not much extended.

- Methanol seemed to get more stable CAI combustion within larger speed ad load ranges than the other two fuels.

Fig.9 shows the maximum combustion temperature for the three fuels at $\mathrm{EVC}=-85^{\circ} \mathrm{CA}$ and $\mathrm{SOI}=120^{\circ} \mathrm{CA}$. It appears that the maximum combustion temperature varied mainly with the load. Methanol shows higher combustion temperature than gasoline and methanol due to higher output.

Fig.10 and 11 shows the start of combustion and combustion duration respectively for the three fuels at the conditions mentioned. It is observed that with CAI combustion, methanol and ethanol had similar start timing of combustion and combustion duration as gasoline at all engine speed tested. This indicates that the oxygenate fuels can obtain CAI combustion as good as gasoline fuel. 


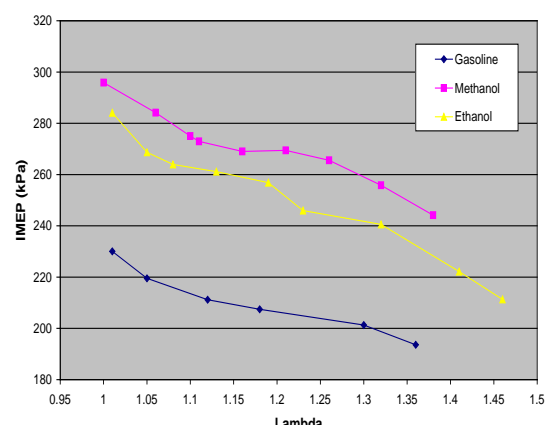

(a) IMEP

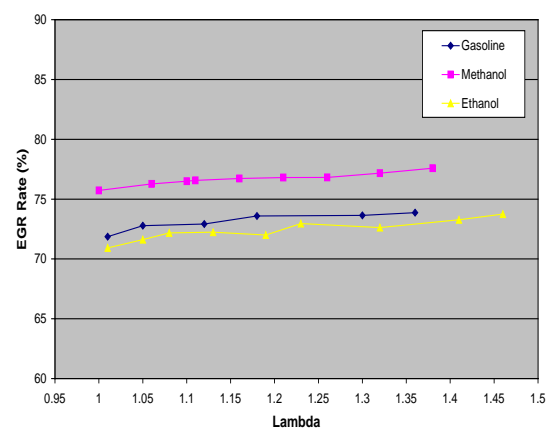

(d) EGR trapped rate

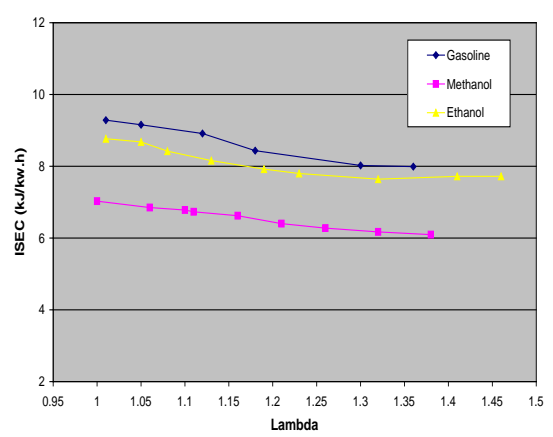

(g) Indicated specific energy consumption

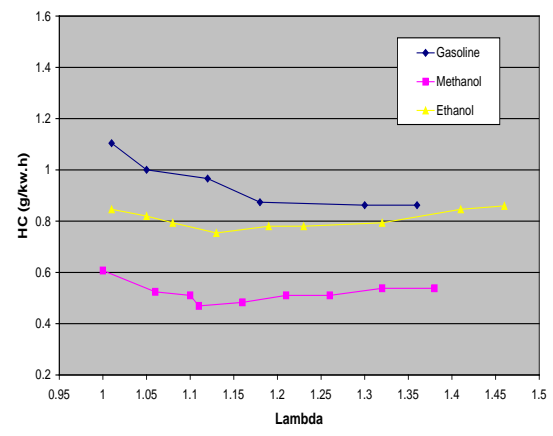

(j) HC emission

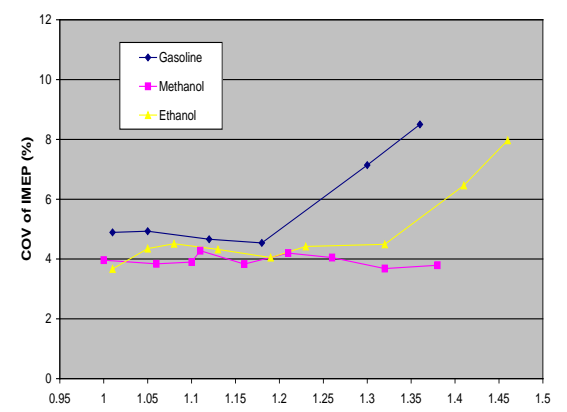

(b) COV of IMEP

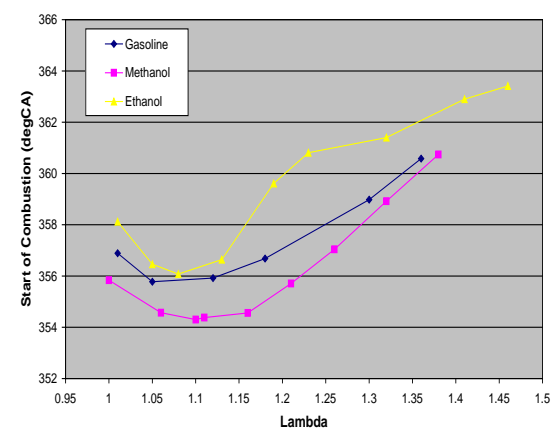

(e) start of combustion (CA at 10\% burn)

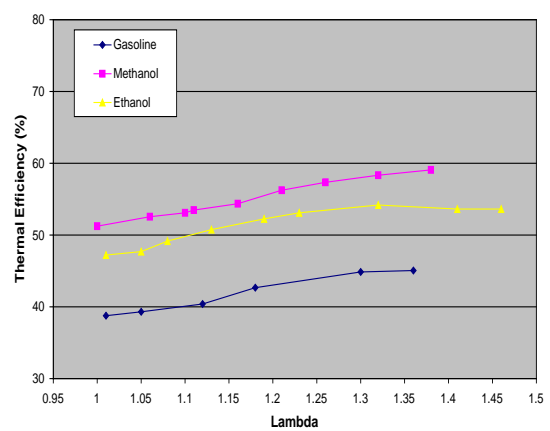

(h) Indicated thermal efficiency

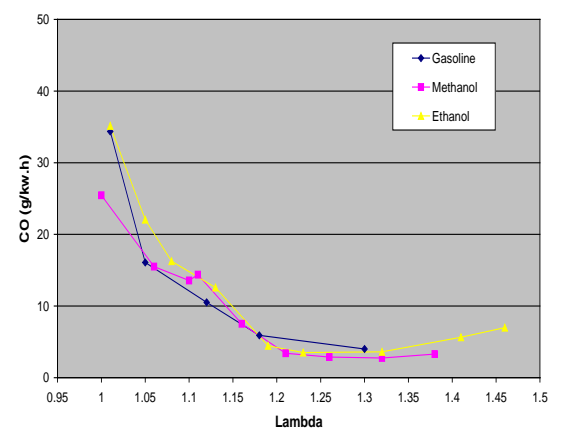

(k) CO emission

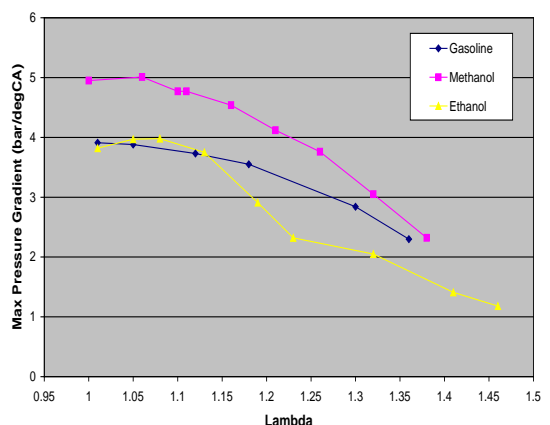

(c) Max pressure gradient

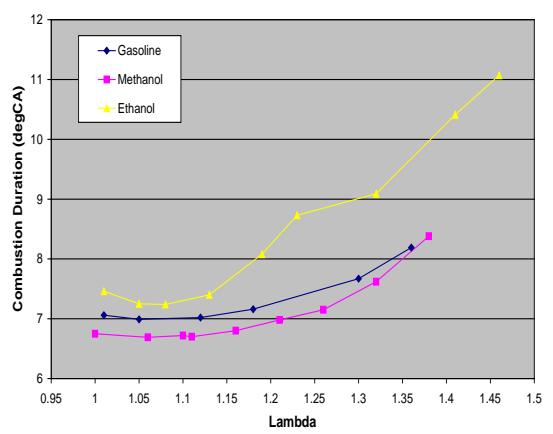

(f) Combustion duration (10-90\% burn)

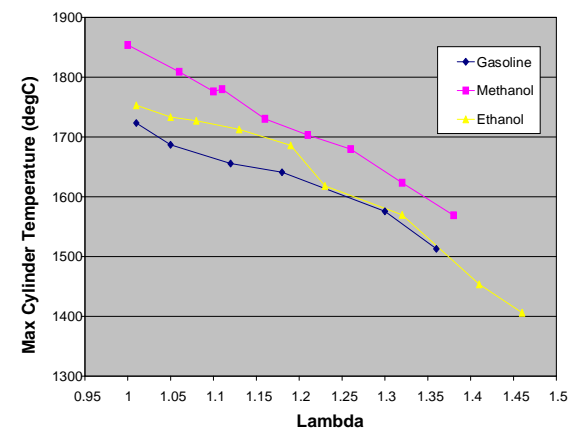

(i) Max cylinder temperature

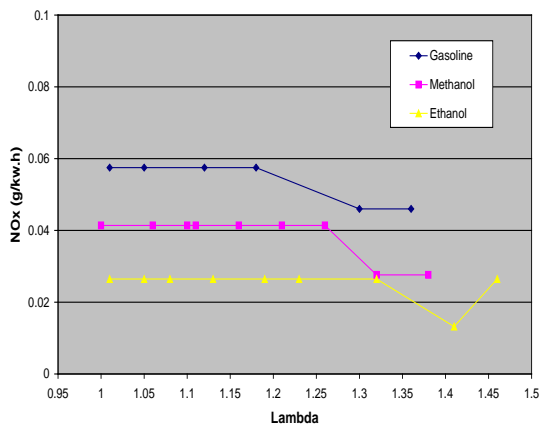

(l) NOx emission

Fig.7 CAl combustion characteristics with Lambda for gasoline, methanol and ethanol $\left(E V C=-85^{\circ} \mathrm{CA}, \mathrm{SOI}=120^{\circ} \mathrm{CA} n=1800 \mathrm{rpm}\right)$ 


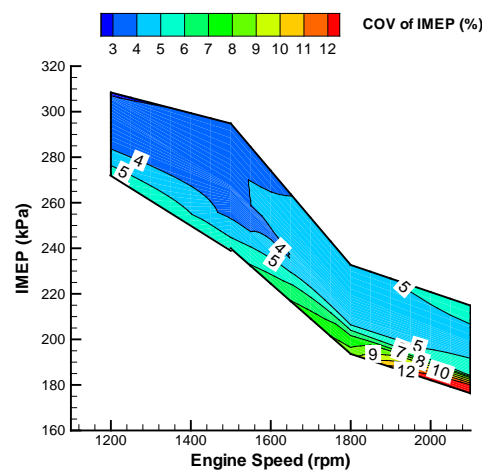

(a) Gasoline

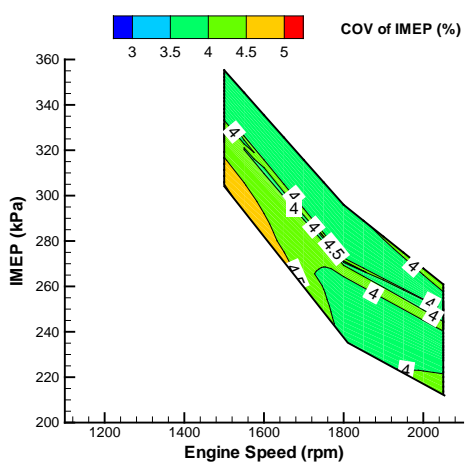

(b) Methanol

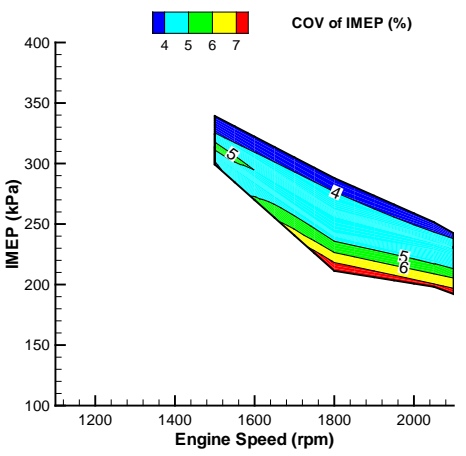

(c) Ethanol

Fig. 8 COV of IMEP for different fuels at EVC $=-85^{\circ} \mathrm{CA}$ and $\mathrm{SOI}=120^{\circ} \mathrm{CA}$

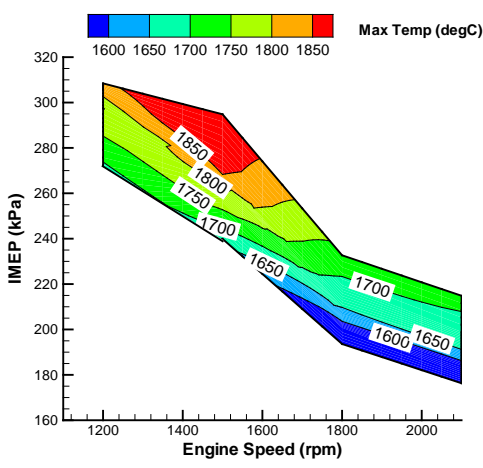

(a) Gasoline

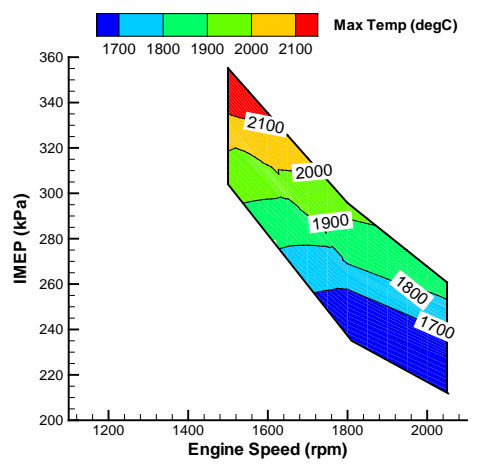

(b) Methanol

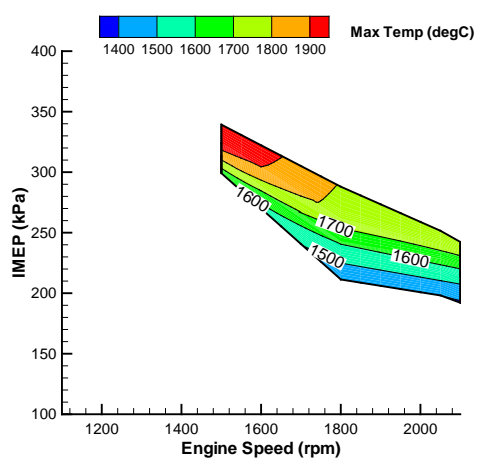

(c) Ethanol

Fig.9 Maximum cylinder temperature for different fuels at $\mathrm{EVC}=-85^{\circ} \mathrm{CA}$ and $\mathrm{SOI}=120^{\circ} \mathrm{CA}$

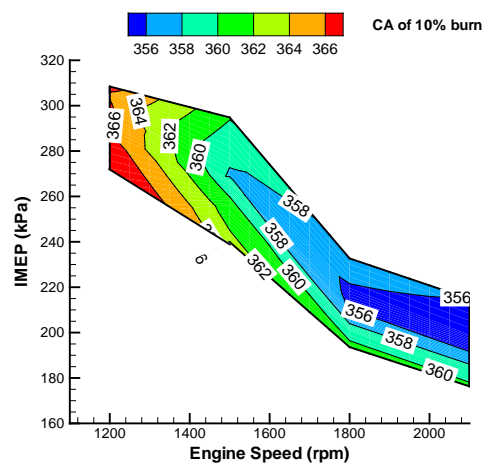

(a) Gasoline

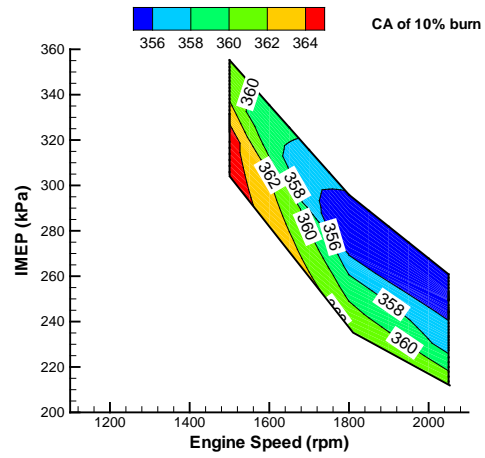

(b) Methanol

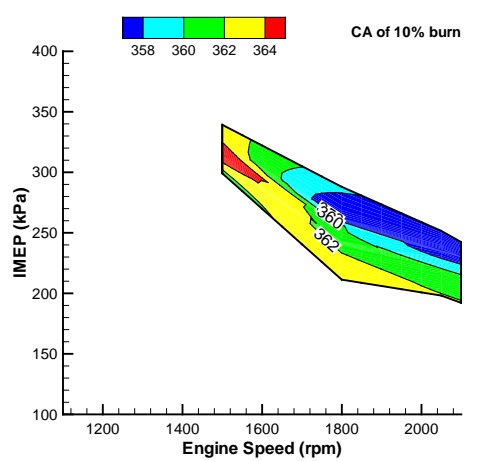

(c) Ethanol

Fig. 10 Start of combustion for different fuels at $\mathrm{EVC}=-85^{\circ} \mathrm{CA}$ and $\mathrm{SOI}=120^{\circ} \mathrm{CA}$

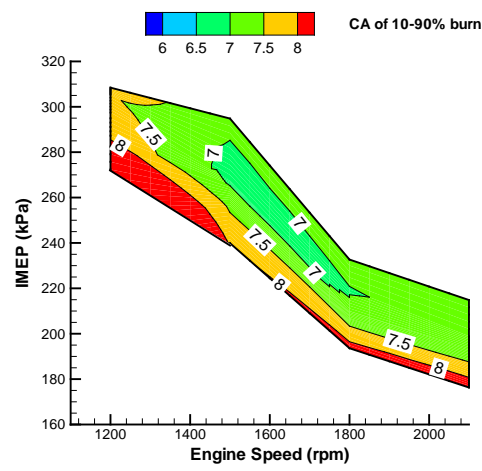

(a) Gasoline

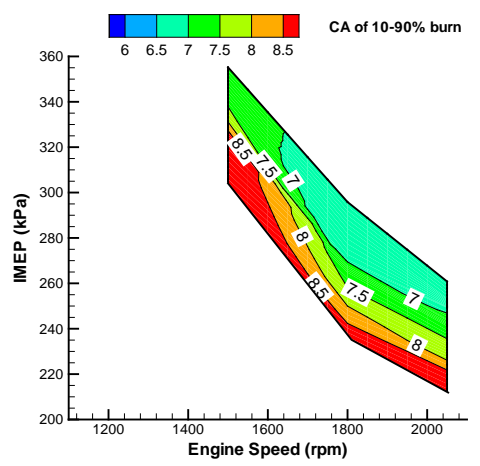

(b) Methanol

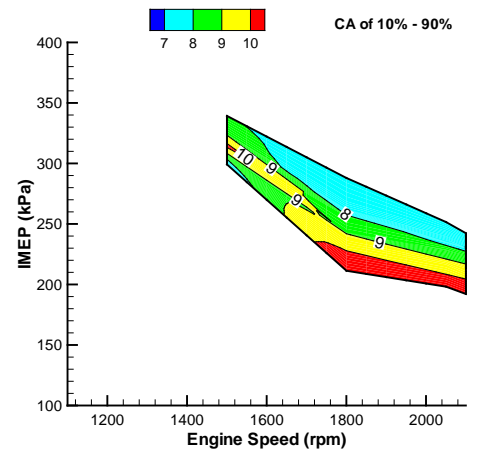

(c) Ethanol

Fig. 11 Combustion duration for different fuels at $\mathrm{EVC}=-85^{\circ} \mathrm{CA}$ and $\mathrm{SOI}=120^{\circ} \mathrm{CA}$ 


\section{SUMMARY AND FUTURE WORK}

From the above test results and analyses, the following points are clear:

- Ethanol and ethanol can achieve CAl combustion under similar conditions as gasoline CAI combustion requires on direct injection SI engines.

- In CAl combustion, methanol can produce more output and give higher fuel conversion efficiency than ethanol which is then better than gasoline.

- CAl combustion of methanol and ethanol gives less $\mathrm{HC}$ and NOx emissions than gasoline CAI combustion.

However, the above test results also show some contradictory points which remain unclear and need further investigate in the future. One of them is why gasoline fuel shows much better CAl combustion characteristics than methanol and ethanol at the EVC of - shows that dense liquid and vapor phases of gasoline spray were present in a short period after injection. Then both phases spread across the cylinder at the end of the intake stroke and continue to extend in the early compression process. In late stage of the compression process, although the liquid phase disappeared from the LIF images, the vapor phase (i.e. air/gasoline mixture) was not distributed uniformly within the cylinder. This non-uniformed mixture distribution will undoubtedly affect auto-ignition and CAI combustion. In addition, liquid phase and non-uniformed vapor phase distributions also cause a complicated thermal distribution as the vaporizing of different amount of fuel droplet in different patches leads to different temperature drops. The nonuniformed thermal distribution will further increase the impact on auto-ignition and CAl combustion. If large amount of EGR or burnt gas residuals are trapped in the cylinder for CAI combustion, distributions air/fuel/EGR mixing and temperature can be much more complicated.

For methanol and ethanol cases, the fuel/air/EGR mixture distribution and thermal distribution are different from

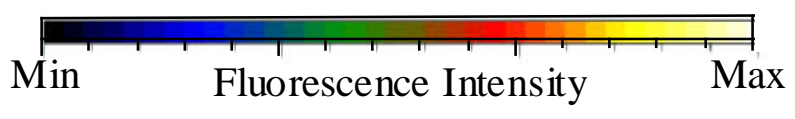

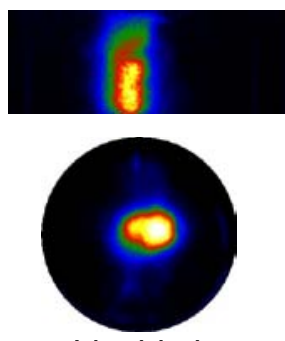

Liquid phase
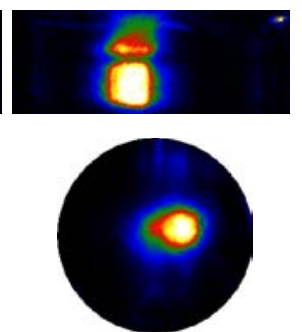

Vapor phase

(a) $130^{\circ} \mathrm{CA}$

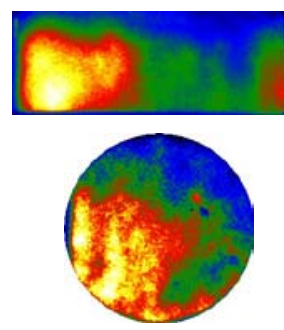

Liquid phase
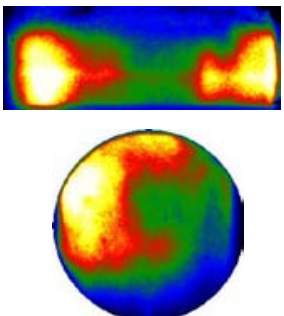

Vapor phase

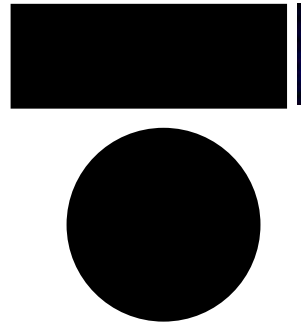

Liquid phase

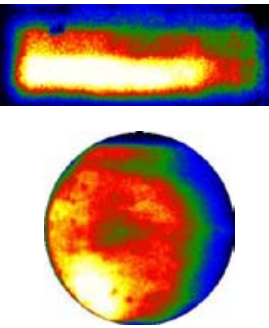

Vapor phase

(b) $180^{\circ} \mathrm{CA}$

Fig.12 Distribution of liquid and vapour phases of gasoline fuel in upper part of the cylinder at SOI of $120^{\circ} \mathrm{CA}[19]$

$70^{\circ} \mathrm{CA}$ while methanol demonstrates much better CAI combustion than gasoline at the EVC of $-85^{\circ} \mathrm{CA}$. In other wards, the relative CAl combustion characteristics of the three fuels seem to vary with the EVC timing or EGR rate. This definitely attributes to their different fuel properties. Especially, the oxygenate fuels have 2-3 times higher vaporizing heat, 1.5-2 times lower heat value and higher auto-ignition temperature than those of gasoline. These fuel properties may provide a fundamental effect in mixture formation and therefore demonstrate differences in self-ignition and CAI combustion processes.

Fig.12 shows distribution of liquid and vapor phases during gasoline/air mixing in the upper part of the cylinder at the SOI of $120^{\circ} \mathrm{CA}$ [19]. These LIF (laser induced fluorescence) images were taken on the same engine with original SI operating setup (using original cam in Fig.2) and fuelled with gasoline. The engine was fitted with a quartz ring window under the cylinder head and a quartz piston top to provide optical accesses. It clearly those in the gasoline case, and could be even more complicated than gasoline case due to much higher vaporizing heat and much lower heat value. In order to understand CAI combustion with different EVC timing or EGR rate for the three fuels, air/fuel/EGR mixture formation and thermal distribution will be investigated in the future by using optical diagnostics.

Another contradictory point is why gasoline fuel gives higher NOx emission with lower combustion temperature than the two oxygenate fuels at the EVC of $-70^{\circ} \mathrm{CA}$. Although less EGR rate is one of reasons to increase NOx emission for gasoline (Fig.6(d)), other root causes still need to investigate by measuring and analyzing air/fuel/EGR mixing and thermal distribution.

Injection timing is another important factor to be able to significantly affect CAI combustion of methanol and ethanol. Injection in the exhaust process may exhibit different CAl combustion characteristics with injection in 
the intake process because fuels have been greatly vaporized and mixed with air and residuals, or in other words, re-conditioned or reformed, during the recompression process. This investigation in the future also helps to understand CAI combustion differences of methanol and ethanol on port injection SI engines and on direct injection SI engines.

\section{ACKNOWLEDGMENTS}

This research is financially supported by the EPSRC (Engineering and Physical Science Research Council) in UK and additional support from Jaguar Cars Ltd is also acknowledged.

\section{REFERENCES}

1. John E. Dec and Magnus Sjöberg, Aparametric Study of $\mathrm{HCCl}$ Combustion - the Sources of Emissions at Low Loads and the Effects of GDI Fuel Injection, SAE paper 2003-01-0752

2. T. Tsurushima, N. Shimazaki and Y. Asaumi, Gas Sampling Analysis of Combustion Process in a Homogeneous Charge Compression Ignition Engine, International Engine Research, Vol.1, No.4, 2000

3. M. Christensen, A. Hultqvist and B. Johansson, Demonstrating the Multi Fuel Capability of a Homogeneous Charge Compression Ignition Engine with Variable Compression Ratio, SAE paper 199901-3679

4. T.W. Ryan III, T.J. Challahan and D. Mehta, $\mathrm{HCCl}$ in a Variable Compression Ratio Engine - Effects of Engine Variables, SAE paper 2004-01-1971

5. J. Li, H. Zhao, N. Ladommatos, Research and Development of Controlled Auto-Ignition (CAI) Combustion in a 4-Stroke Multi-Cylinder Gasoline Engine, SAE paper 2001-01-3608, 2001

6. P.A. Caton, A.J. Simon, J.C. Gerdes and C.F. Edwards, Residual-Effected Homogeneous Charge Compression Ignition at a Low Compression Ratio Using Exhaust Reinduction, Internationl Journal of Engine Research, Vol.4, No.3, p163-177, 2003

7. A. Fuerhapter, W.F. Piock and G.K. Fraidl, CSI Controlled Auto Ignition - the Best solution for the Fuel Consumption - Versus Emission Trade-Off?, SAE paper 2003-01-0754

8. R. Chen, N. Milovanovic, J. Turner and D. Blundell, The Thermal Effect of Internal Exhaust Gas Recirculation on Controlled Auto Ignition, SAE paper 2003-01-0751

9. T. Urushihara, K. Hiraya, A. Kakuhou and T. Itoh, Expansion of $\mathrm{HCCl}$ Operating Region by the Combination of Direct Injection, Negative Valve Overlap and Internal Fuel Reformation, SAE paper 2003-01-0749

10. Y. Urata, M. Awasaka, J. Takanashi, T. Kakinuma, T. Hakozaki and A. Umemoto, A Study of Gasoline Fuelled $\mathrm{HCCl}$ Engine Equipped with an Electromagnetic Valve Train, SAE paper 2004-011898
11. R.J. Osborne, G. Li, S.M. Sapsford, J. Stokes, T.H. Lake and M.R. Heikal, Evaluation of $\mathrm{HCCl}$ for Future Gasoline Powertrains, SAE paper 2003-01-0750

12. R. H. Standing, N. Kalian, T. Ma, H. Zhao, M. Wirth and A. R. Schamel, Effects of Injection Timing and Valve Timing on CAI Operation in a Multi-Cylinder DI Gasoline Engine, SAE paper 2005-01-0132, 2005

13. Yufeng Li, Hua Zhao, Nikolaos Brouzos, Tom Ma and Ben leach, Effect of Injection Timing on Mixture and CAI Combustion in a GDI Engine with an AirAssisted Injector, SAE paper 2006-01-0206

14. Aaron Oaklay, Hua Zhao, Nicos ladommatos and Tom Ma, Dilution Effects on the Controlled AutoIgnition (CAI) Combustion of Hydrocarbon and Alcohol Fuels, SAE paper 2001-01-3606

15. Hui Xie, Zhipeng Wei, Bangquan $\mathrm{He}$ and Hua Zhao, Comparison of $\mathrm{HCCl}$ Combustion Respectively Fuelled with Gasoline, Ethanol and Methanol Through The Trapped Residual Gas Strategy, SAE paper 2006-01-0635

16. G. Cathcart and C. Zavier, Fundamental Characteristics of an Air-Assisted Direct Injection

17. Combustion System as Applied to a 4 Stroke Automotive Gasoline Engines, SAE paper 2000-010256

18. Yufeng Li, Hua Zhao, Nikolaos Brouzos and Tom Ma, Parametric Study on CAO Combustion in a GDI Engine with an Air-Assisted Injector, SAE paper 2007-01-0196

19. Y. Li, H. Zhao, N. Brouzos and B. Leach, Managing Controlled Auto-Ignition Combustion by Injection on a Direct Injection Gasoline Engine, Proc IMechE, vol. 221, Part D: Journal of Automobile Engineering, pp1125-1136, 2007

\section{CONTACT}

Professor Hua Zhao

School of Engineering and Design

Brunel University

Uxbridge, Middlesex, UB8 3PH

U.K.

Email: Hua.Zhao@brunel.ac.uk

Dr Yufeng Li

Ford Motor Company

Dunton Technical Centre

Room GB-15/2A-C08-B

Basildon, Essex, SS15 6EE

U.K.

Email: yli54@ford.com 